\title{
Retraction
}

\section{Retracted: An Improved Particle Swarm Optimisation Method for Performance Evaluation of Instructors}

\author{
Security and Communication Networks
}

Received 15 November 2022; Accepted 15 November 2022; Published 29 November 2022

Copyright ( 2022 Security and Communication Networks. This is an open access article distributed under the Creative Commons Attribution License, which permits unrestricted use, distribution, and reproduction in any medium, provided the original work is properly cited.

Security and Communication Networks has retracted the article titled "An Improved Particle Swarm Optimisation Method for Performance Evaluation of Instructors" [1] due to concerns that the peer review process has been compromised.

Following an investigation conducted by the Hindawi Research Integrity team [2], significant concerns were identified with the peer reviewers assigned to this article; the investigation has concluded that the peer review process was compromised. We therefore can no longer trust the peer review process, and the article is being retracted with the agreement of the Editorial Board.

\section{References}

[1] Y. Mu, "An Improved Particle Swarm Optimisation Method for Performance Evaluation of Instructors," Security and Communication Networks, vol. 2022, Article ID 3333005, 7 pages, 2022.

[2] L. Ferguson, "Advancing Research Integrity Collaboratively and with Vigour," 2022, https://www.hindawi.com/post/advancingresearch-integrity-collaboratively-and-vigour/. 


\title{
An Improved Particle Swarm Optimisation Method for Performance Evaluation of Instructors
}

\author{
Mu Yuanhong (iD \\ School of Economics and Trade Guangdong Mechanical and Electrical Polytechnic, Guangzhou, China \\ Correspondence should be addressed to Mu Yuanhong; 2014020014@gdmec.edu.cn
}

Received 26 November 2021; Revised 5 January 2022; Accepted 7 January 2022; Published 14 February 2022

Academic Editor: Muhammad Arif

Copyright @ $2022 \mathrm{Mu}$ Yuanhong. This is an open access article distributed under the Creative Commons Attribution License, which permits unrestricted use, distribution, and reproduction in any medium, provided the original work is properly cited.

\begin{abstract}
Performance evaluation of counselors plays a vital role for education industry (schools, colleges, universities, and vocational colleges). The problem can be stated with the phrases; how to design reasonable and appropriate performance indicators? The objective of this research is to design an effective performance evaluation. The purpose of this study is to explore a new method of performance evaluation that combines strategic goals with personal development goals. The purpose of performance evaluation is to better motivate the enthusiasm of counselors. With the methodology, a new issue faced at modern colleges and universities is being resolved. Therefore, for explaining methodology, this study has carried out the application analysis of the fusion particle swarm algorithm (FPSA) in the performance evaluation of instructors. First, on the basis of comprehensive analysis of performance evaluation, it discusses the advantages and disadvantages of university performance evaluation. Secondly, particle swarm and fuzzy comprehensive evaluation methods are used in the research of instructor performance evaluation. Pass the superiority of this assessment system. Index parameter evaluation is from 2.5 to 3.0. The range indicates an excellent value. In result this improved particle swarm can be compared with the state of the art (Liu et al., 2019). In conclusive remarks, this study is to provide state-of-the-art study for the current research on the topic of instructor performance appraisal in colleges and universities.
\end{abstract}

\section{Introduction}

The performance evaluation theory in human resource management is widely used, and companies inspect, measure, and evaluate employees through performance evaluation to improve the economic efficiency and organizational management level of the company [1, 2]. Government public departments and universities have gradually begun to explore the performance evaluation model, in order to develop a scientific and effective evaluation system to improve work efficiency [3]. Therefore, the introduction of performance evaluation theory into the work evaluation of counselors and the scientific and comprehensive evaluation of the work of counselors are important measures to motivate the work of college counselors $[4,5]$.

\section{Literature Review}

At present, many colleges and universities have generally adopted a combination of qualitative and quantitative performance evaluations for the group of instructors, with a quantitative approach, and the work attitude, work ability, and work performance have been included in the evaluation content [6-9]. However, subjective selection methods are mostly used in the selection of evaluation indicators. In terms of finalizing the evaluation content index system and the weight of each content index, the subjectivity is too obvious. The coach performance evaluation system constructed in this way is ineffective. The expected evaluation effect cannot motivate the team of counselors to actively tap their own potential and create higher performance [10]. And because the counselor's own work has not received a comprehensive and accurate response, it will dampen their enthusiasm for work to a certain extent $[11,12]$.

Looking at the current literature on the performance appraisal of counselors' daily work, most of the research focuses on the analysis of the current status of the performance appraisal system for counselors in colleges and universities. Reasonable and effective performance appraisal 
system puts forward its own countermeasures and suggestions [13-15]. Landy et al. believe that performance evaluation is the central function of human resource management because it is a test of the content and early input effects of many human resource management activities [16]. Cleveland et al. pointed out that performance evaluation provides relevant information for many personnel decision-making, including salary increase, job recommendation, transfer, training plan, and employee development and performance feedback [17]. Studies by Maye and Davis have shown that effective use of performance evaluation.

Systems can provide opportunities for building organizational trust [18]. Pettijohn and others believe that performance appraisal is conducive to the functioning of other human resource management activities [19]. However, the previous research on the performance appraisal system of counselors' daily work has not carried out in-depth construction of the performance appraisal index system for counselors in higher vocational colleges and lacks strong operability [20, 21].

Many colleges and universities have realized the importance of appraisal and have invested a lot of energy in the work of performance appraisal $[22,23]$. However, there are still many problems in the performance appraisal work of counselors. How to evaluate the performance of the instructor groups in colleges and universities is a problem faced by the construction of the teaching staff of colleges and universities. Based on the analysis and research on the status quo of the performance appraisal of university counselors, the idea of constructing the performance appraisal system is put forward. The establishment of the human resource performance appraisal system in universities is a complex and important task. Most universities are still in the initial and exploratory stage, and similar problems exist in the implementation of performance appraisal. Therefore, this article attempts to explore scientific and reasonable methods and approaches for human resource performance evaluation in colleges and universities through the analysis and research of the current situation of human resource performance evaluation of counselors and the construction of human resource performance evaluation system.

\section{Methodology}

Methodology consists of two sections, counselor performance evaluation and performance evaluation, based on particle swarm intelligence.

3.1. Counselor Performance Evaluation. The performance appraisal system for instructors has always been a more complicated system project embodied in the construction of college appraisal [23-25]. Regarding the various indicators and factors in the assessment system, such as how to formulate specific indicators for the instructor's assessment, how to make the indicators more scientific and objective, and how to stimulate the enthusiasm of the instructor to better participate in the assessment influence in the system $[26,27]$. Many factors outside the appraisal system will also have an impact on the performance of the counselor, thereby affecting the effectiveness of the counselor's performance appraisal $[28,29]$. Therefore, in the college system, how to manage the performance of counselors more effectively is not only a problem that the student work department should think about but also a problem that the management of other departments of the university should think about together. Figure 1 describes the technical roadmap for performance evaluation.

In the performance appraisal stage, it is necessary to realize the unification of competency description and performance appraisal indicators [30,31]. Performance results are quantified, focusing on past short-term goals. Generally speaking, the performance results of counselors are mainly evaluated by indicators such as student class attendance rate, recognition status, make-up exam rate, retake rate, dropout rate, disciplinary violations, and safety accident occurrences $[32,33]$. Competency assessment has a wide range and focuses on the future. It mainly examines the current strengths and weaknesses of employees and the gap between the existing competence and the current and future job competence requirements. The results are used as the basis for employee development and career planning index. The combination of the two is mainly achieved through the weight between performance and competence. Figure 2 describes the competency-based performance management model of college counselors.

3.2. Performance Evaluation Based on Particle Swarm. This study first adopts the literature analysis method, uses the function analysis method, the performance method, and the situation method to analyze the competencies that the college counselors should have, summarizes these competencies to obtain multiple competencies of the counselors, then uses the Delphi method to define each competency, and finally designs a questionnaire on the competence of college counselors, test college counselors, uses SPSS13.0 to analyze the survey results by exploratory factors, and obtains the four competency models [34]. Dimensions: in order to verify the results of exploratory factor analysis, the new samples were investigated with the college counselor competency questionnaire, and the structural equation modeling software AMOS4.0 was used for confirmatory analysis, and finally, the competency model of college counselors was obtained:

$$
\left\{\begin{array}{l}
y=\beta_{0}+\beta_{1} x_{1}+\cdots+\beta_{m} x_{m}+\varepsilon, \\
\varepsilon \sim N\left(0, \sigma^{2}\right)
\end{array}\right.
$$

which is an unknown parameter that has nothing to do with $x$. Now, we get $n$ independent observation data, where $a$ is the observation value of $x_{1}, x_{2}, \ldots, x_{m} . b$ is the observed value of $y$.

$$
\left\{\begin{array}{l}
b_{i}=\beta_{0}+\beta_{1} a_{i 1}+\cdots+\beta_{m} a_{i m}+\varepsilon_{i}, \\
\varepsilon_{i} \sim N\left(0, \sigma^{2}\right), i=1, \ldots, n
\end{array}\right.
$$

Among them, the parameter $\beta_{0}, \beta_{1}, \ldots, \beta_{m}$ is estimated by the least square method, that is, the estimated value should be selected. The fitting error $e=Y-\widehat{Y}$ is called the 


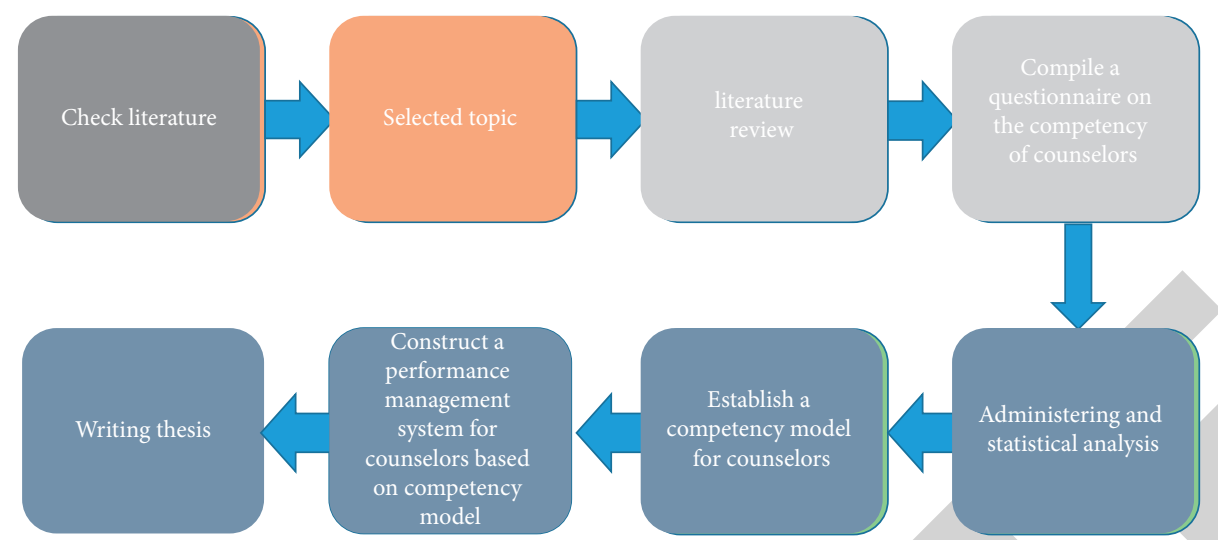

Figure 1: Technical roadmap for performance evaluation.

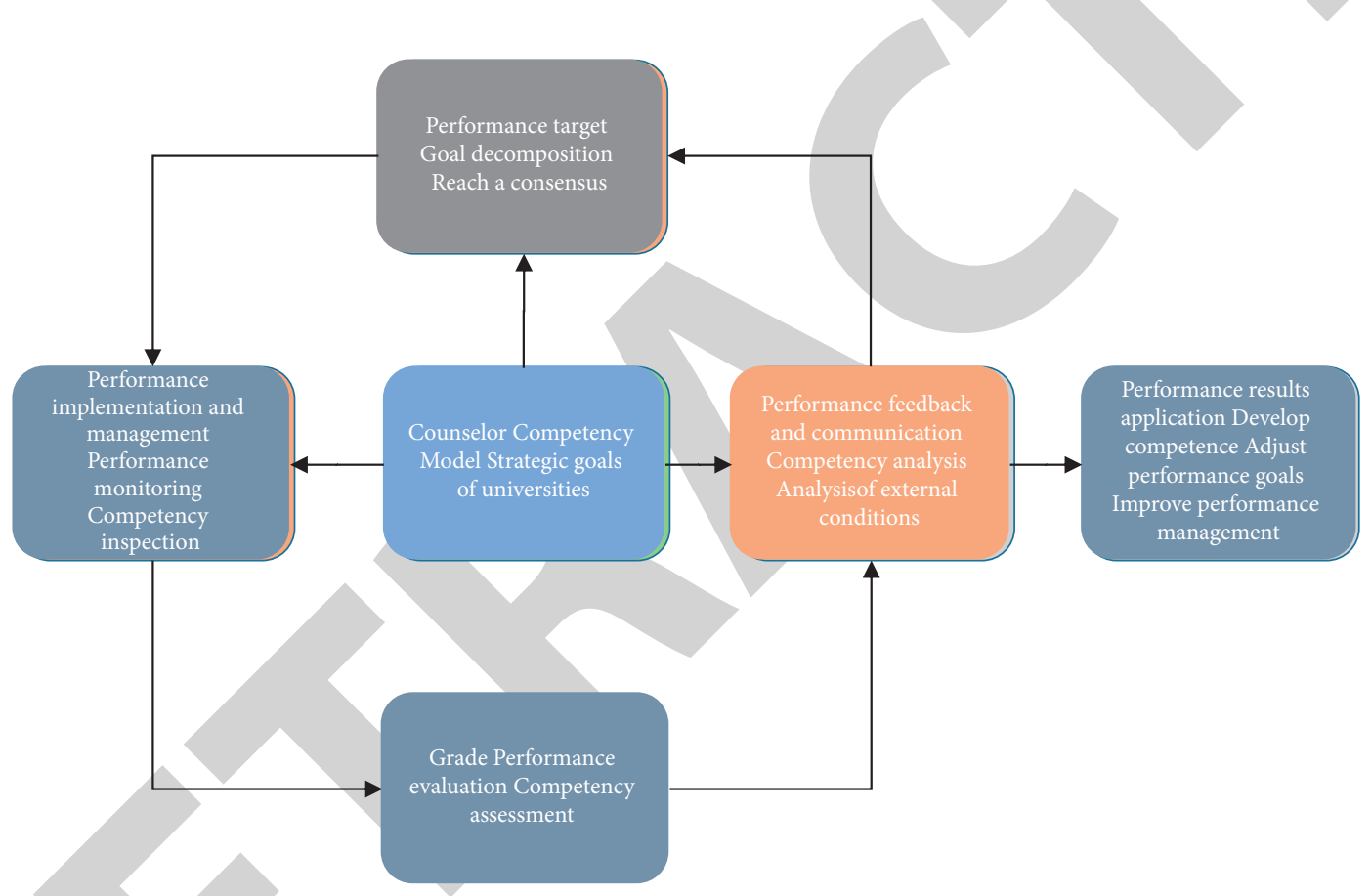

FIGURE 2: Performance management mode of college counselors based on competence.

residual and can be used as an estimate of the random error $\varepsilon$ :

$$
\mathrm{Q}=\sum_{i=1}^{n} e_{i}^{2}=\sum_{i=1}^{n}\left(b_{i}-\widehat{b}_{i}\right)^{2}
$$

According to niche thinking, similar particles will gradually gather as they evolve to form several niche subgroups. In this paper, the Euclidean distance is used to represent the particle distance, and a strategy is designed to divide the niche subgroups [35]. The distance $x_{a}, x_{b} \in \Omega$ between any two particles in the particle space $\Omega$ is expressed by the Euclidean distance $D\left(x_{a}, x_{b}\right)$ as

$$
D\left(x_{a}, x_{b}\right)=\sqrt{\sum_{i=1}^{3}\left(x_{a}^{i}-x_{b}^{i}\right)^{2}}
$$

where $x_{a}^{i}$ and $x_{b}^{i}$ are the parameter values of 2 particle codes, respectively, $X$ is the particle space, and $\Omega$ is the set of small and medium habitat subgroups:

$$
D\left(x_{a}, x_{s}\right)=\sqrt{\sum\left(x_{a}^{i}-\left(o\left(X_{s}\right)\right)^{i}\right)^{2}} .
$$

The center point of the niche subgroup is defined as the center position of all particles, and the center point changes when the particles join the niche subgroup:

$$
\left(o\left(X_{s}\right)\right)^{i}=\frac{x_{a}^{i}+\left(o\left(X_{s}\right)\right)^{i}}{2} .
$$

If

particle $x_{a} \in \Omega$ satisfies $\min \left\{D\left(x_{a}, X_{k}\right) \mid X_{k} \subset X\right\}=D\left(x_{a}, X_{s}\right)$, the particles belong to the same niche subgroup. If only part of it is satisfied, the particle alone serves as a niche subgroup, where $\varepsilon$ is the average distance between all particles. 
Based on the above analysis, all particles are divided into several niche subgroups, and the global optimal particle selection is performed. According to the multiobjective function, the optimal particle is selected from each niche subgroup as the optimal particle set, and the scale of each niche subgroup is calculated, that is, the number of particles in each niche subgroup. The particle with the smallest size of the niche subgroup belonging to the optimal particle set is selected as the global optimal particle. The method of combining multiobjective functions and niche subgroups to obtain optimal particles can not only select the optimized particles but also retain the diversity of particles.

According to the selected global optimal update particles, the speed and position of the particles are updated as follows:

$$
\begin{aligned}
& v_{x_{a}^{i}}^{t+1}=w v_{x_{a}^{i}}^{t}+c_{1} r_{1}\left(p_{x_{a}^{i}}^{t}-s_{x_{a}^{i}}^{t}\right)+c_{2} r_{2}\left(g_{i}^{t}-s_{x_{a}^{i}}^{t}\right), \\
& s_{x_{a}^{i}}^{t+1}=s_{x_{a}^{i}}^{t}+v_{x_{a}^{i}}^{t+1},
\end{aligned}
$$

where $w$ is the inertia weight, $r_{1}$ is a random number uniformly distributed between $(0,1), c_{1}$ and $c_{2}$ are the learning factors, $v_{x_{a}^{i}}^{t}$ and $s_{x_{a}^{i}}^{t}$ are the velocity and position of the particle in the first generation, respectively, $p_{x_{a}^{i}}^{t}$ is the local optimal position of the particle, and $g_{i}^{t}$ is the global optimal position of the particle swarm.

According to the relevant factors of the task completion, the task completion efficiency, task completion rate, and other indicators are selected to evaluate the task completion. The evaluation of task completion has a certain degree of uncertainty. Because certain factors of task pricing are fuzzy, the fuzzy comprehensive evaluation method has been widely used, but the determination of the fuzzy membership degree has a certain degree of arbitrariness, which is in line with objective reality. The membership function can be obtained in long-term "learning." Therefore, based on the theory of set pair analysis, this study takes uncertainty and certainty as a system to study, with the help of the law of mutual connection between certainty and uncertainty in this system and mutual transformation under certain conditions. For high and low indicators, we use different data standardization methods.

For positive indicators,

$$
z_{i j}=\frac{x_{i j}-\min \left(x_{i j}\right)}{\max \left(x_{i j}\right)-\min \left(x_{i j}\right)} .
$$

For negative indicators,

$$
z_{i j}=\frac{\max \left(x_{j}-x_{i j}\right)}{\max \left(x_{i j}\right)-\min \left(x_{i j}\right)} .
$$

Finally, we get the normalized matrix:

$$
z=\left(z_{i j}\right)_{n \times m}=\left[\begin{array}{cccc}
x_{11} & x_{12} & \ldots & x_{14} \\
x_{21} & x_{22} & \ldots & x_{24} \\
\ldots & \ldots & \ldots & \ldots \\
x_{20661} & x_{20662} & \ldots & x_{20664}
\end{array}\right] .
$$

Calculate the proportion of the $i$ th program index under the $j$ th index $p_{i j}$ :

$$
p_{i j}=\frac{z_{i j}}{\sum_{i=1}^{n} z_{i j}} .
$$

Calculate the entropy value of the $j$ th index:

$$
e_{j}=-k \sum_{i=1}^{n} p_{i j} \text { in }\left(p_{i j}\right) \text {. }
$$

Normalize the difference coefficient to calculate the weight:

$$
w_{j}=\frac{g_{j}}{\sum_{k=1}^{m} g_{k}} .
$$

Using the previously determined weight vector $W$ and the identity matrix $Q$, the weighted identity matrix $R$ of each evaluation object and the ideal plan can be determined:

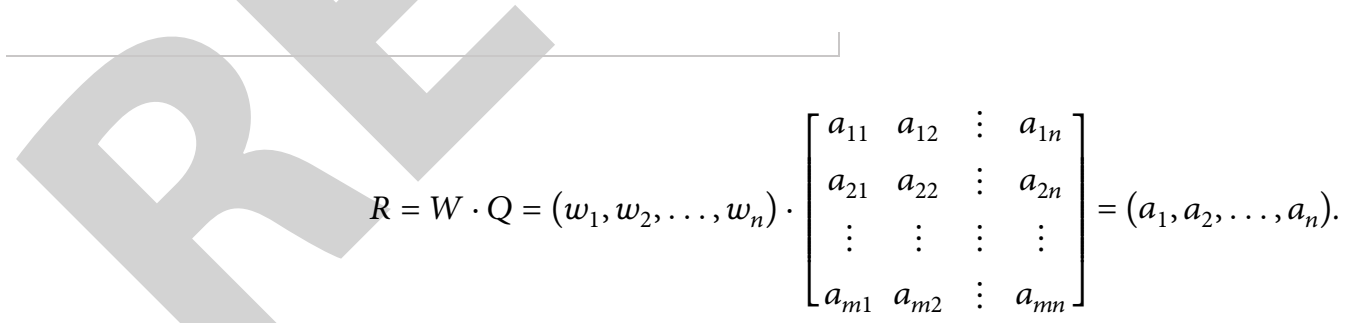

\section{Results and Discussion}

Results and discussion are mentioned and are much helpful to show the variance $o$ results.

According to the value of the same degree matrix $R$, the pros and cons of the $m$ evaluated objects are determined. The larger the value of $a_{j}$, the better the evaluation. The abovementioned evaluation model process standard is shown in Table 1.
It can be seen from Table 1 that when the index parameter is $2.5-3$, the evaluation result is excellent. When the index parameter is $2-2.5$, the evaluation result is better. When the index parameter is $1.5-2$, the evaluation result is good. When the index parameter is $1-1.5$, the evaluation result is poor. When the index parameter is $0-1$, the evaluation result is poor. Figure 3 describes the results of the comparison of the performance optimization of the instructors. 
TABLE 1: Summary table of explanation of total variance.

\begin{tabular}{lccccc}
\hline Implementation effect & Excellent & Better & Good & Poor & Bad \\
\hline Index parameter & $2.5-3$ & $2-2.5$ & $1.5-2$ & $1-1.5$ & $0-1$ \\
\hline
\end{tabular}

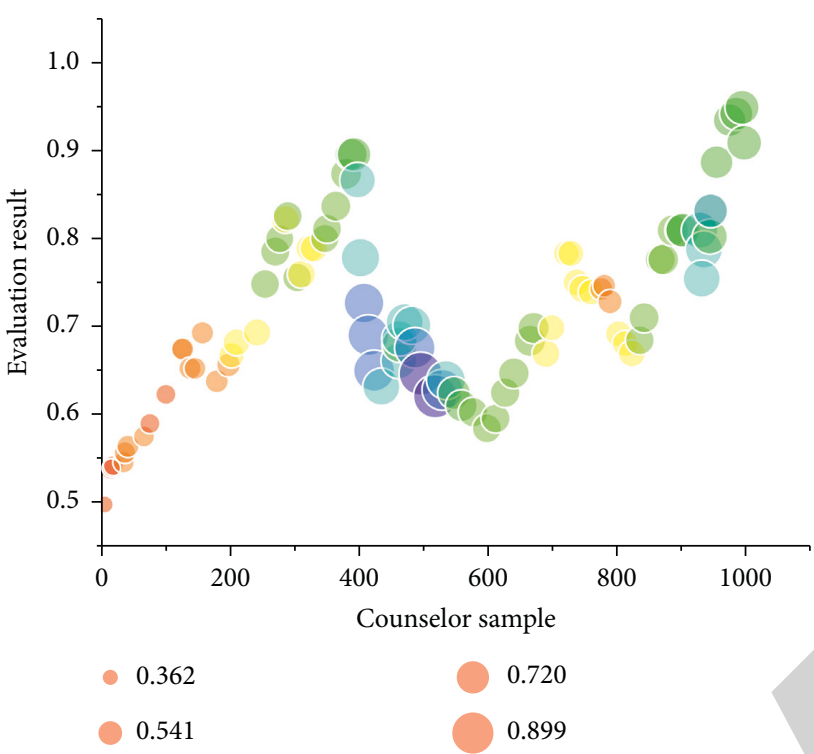

Figure 3: Counselor performance optimization comparison results.

The content of the counselor group evaluation is a summary of the work content of each individual, so the individual counselor evaluation indicators are consistent with the group evaluation indicators except for the "Counselor Team Building." Figure 4 shows the comparison among FPSI and state-of-the-art technique. The current evaluation method is a single evaluation of the individual work of the counselor. Because the performance of a counselor group is also a comprehensive manifestation of the work performance of each counselor, only the performance of the entire group can be improved, and the performance of each counselor can be better reflected. This can help every counselor establish a sense of teamwork and a sense of collective honor, consciously combine their own work goals with the goals of the group in their work, and ultimately achieve the goal of mutual promotion and mutual development. Therefore, in the new individual evaluation plan, we should include the group evaluation situation in the individual evaluation index.

\section{Recaptulation}

The results of the proposed study consist of the index parameter. The maximum range of the proposed method is from 2.5 to 3.0. The proposed method name is fusion particle swarm intelligence (FPSI), whereas the index parameter value of the state-of-the-art method is 1 so the FPSI is $s$.

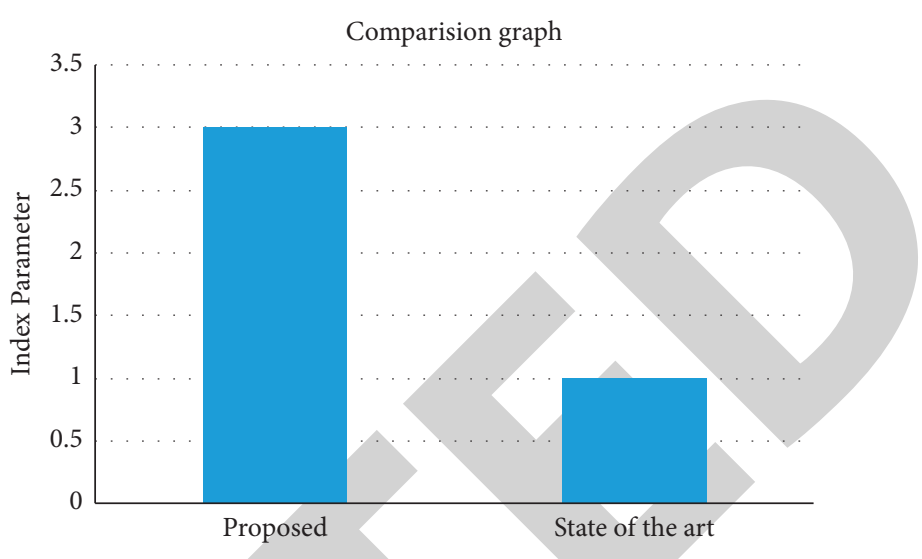

FIgUre 4: Comparison between FPSI and state-of-the-art technique.

\section{Conclusion}

The competency model of college counselors is a multidimensional model is composed of four dimensions: work attitude, values, work ability, and personal charm. These four dimensions reflect the same factor at a higher level. The development method of the competency model of college counselors needs further research. It is necessary to explore in future practice how to better improve and enrich the development methods suitable for the competency characteristics of the counselor's position and improve its accuracy. Whether these methods are suitable for counselors, we need to continue to explore, improve, and enrich them in future practice. The empirical research on human resource management of college counselors based on the competency model boldly introduces the competency characteristics into the human resource management system of college counselors. The program helps to establish a sound counselor human resource management system and improve the overall quality of college counselors.

\section{Data Availability}

The data of used to support the findings of the study are included within article.

\section{Conflicts of Interest}

The author declares that there are no conflicts of interest.

\section{Acknowledgments}

This work was supported by Guangdong Province Educational Science "Thirteenth Five-Year Plan" Party Building Research Project "Analysis of the Deep Integration Mechanism of Party Building Work and Education and Teaching in Colleges and Universities in the New Era-Based on the Curriculum Ideological and Political Perspective" (2019JKDJ029) and Guangdong Quality Engineering Educational Reform Project "Background of the Information Age A comprehensive study on the management mode of 
internship in mechanical and electrical majors-based on the perspective of diagnosis and improvement" (GDJG2019061).

\section{References}

[1] W. Zhu, H. Ma, G. Cai, J. Chen, X. Wang, and A. Li, "Research on PSO-ARMA-SVR short-term electricity consumption forecast based on the particle swarm algorithm," Wireless Communications and Mobile Computing, vol. 2021, no. 6, pp. 1-12, 2021.

[2] S. Zhang and J. Chen, "Optimization of energy-efficient dynamic task assignment for wireless sensor networks based on particle swarm algorithm," Journal of Intelligent and Fuzzy Systems, vol. 20, pp. 1-11, 2021.

[3] M. Zhang, "Prediction of rockburst hazard based on particle swarm algorithm and neural network," Neural Computing \& Applications, pp. 1-11, 2021.

[4] C.-C. Zhang, H.-H. Zhu, Q. Xu, B. Shi, and G.-X. Mei, “Timedependent pullout behavior of glass fiber reinforced polymer (GFRP) soil nail in sand," Canadian Geotechnical Journal, vol. 52, no. 6, pp. 671-681, 2015.

[5] F. Yuan, K. Lv, B. Tang et al., "Optimization design of oilimmersed iron core reactor based on the particle swarm algorithm and thermal network model," Mathematical Problems in Engineering, vol. 2021, no. 4, pp. 1-14, 2021.

[6] H. You, L. Yu, S. Tian et al., "MC-Net: multiple max-pooling integration module and cross multi-scale deconvolution network," Knowledge-Based Systems, vol. 231, Article ID 107456, 2021.

[7] C. Yan, G. Pang, X. Bai, J. Zhou, and L. Gu, "Beyond triplet loss: person Re-identification with fine-grained differenceaware pairwise loss," pp. 1-55, 2020, https://arxiv.org/pdf/ 2009.10295.pdf.

[8] R. A. Ramadan and A. B. Altamimi, "BCLO-brainstorming and collaborative learning optimization algorithms," Machine Learning Paradigms: Theory and Application, , pp. 393-412, Springer, 2019.

[9] G. Wang, W. Li, L. Zhang et al., "Encoder-X: solving unknown coefficients automatically in polynomial fitting by using an autoencoder," IEEE Transactions on Neural Networks and Learning Systems, vol. 99, pp. 1-13, 2021.

[10] C. A. Tuttas, "Job integration factors as predictors of travel nurse job performance," Journal of Nursing Care Quality, vol. 30 , no. 1 , pp. 44-52, 2015.

[11] W. Tang, H. Cha, M. Wei, B. Tian, and X. Ren, "Atmospheric refractivity estimation from AIS signal power using the quantum-behaved particle swarm optimization algorithm," Open Geosciences, vol. 11, no. 1, pp. 542-548, 2019.

[12] L. Sun, W. Li, X. Ning, L. Zhang, X. Dong, and W. He, "Gradient-enhanced softmax for face recognition," IEICE Transactions on Info and Systems, vol. E103.D, no. 5, pp. 1185-1189, 2020.

[13] F. Sun, D. Zhu, M. Liang, and D. Zhang, "Study on formfinding of cable-membrane structures based on particle swarm optimization algorithm," Mathematical Problems in Engineering, vol. 2020, Article ID 1281982, 13 pages, 2020.

[14] X. Chen, "Compensated fuzzy neural network-based music teaching ability assessment model," Computational Intelligence and Neuroscience, vol. 202111 pages, Article ID 3865190, 2021.

[15] H. Muñoz Bautista, J. Canul-Reich, A. Padilla Díaz, J. C. Ponce Gallegos, J. Muñoz Arteaga, and P. D. García González, "Solution of the assignment of schedules problem with the gray wolf optimizer (GWO), applying evolutionary parameters," Research in Computing Science, vol. 147, no. 2, pp. 129-141, 2018.

[16] F. J. Landy, J. L. Barnes-Farrell, and J. N. Cleveland, "Perceived fairness and accuracy of performance evaluation: a follow-up," Journal of Applied Psychology, vol. 65, no. 3, pp. 355-356, 1980.

[17] B. Cleveland, "Developing new approaches to the evaluation of physical learning environments: a return to the origins of post-occupancy evaluation in environmental psychology," 2015.

[18] M. S. Davis and M. A. Mensah, "Performance appraisal of employees in tertiary institutions: a case study of University of Education," Winneba (Winneba Campus), International Journal of Human Resource Studies, vol. 10, 2020.

[19] L. S. Pettijohn, R. S. Parker, C. E. Pettijohn, and O. L. Kent, "Performance appraisals: usage, criteria and observations," Journal of Management Development, vol. 20, no. 9, pp. 754-771, 2001.

[20] F. Idowu Oluwajobi, D. N. Nguyen, and A. Malekmohammadi, "Performance evaluation of four-level modified Manchester modulation format for high-speed optical transmission systems," IET Communications, vol. 13, no. 15, pp. 2344-2351, 2019.

[21] X. Ning, W Li, B Tang, and H He, "BULDP: biomimetic uncorrelated locality discriminant projection for feature extraction in face recognition," IEEE Transactions on Image Processing: A Publication of the IEEE Signal Processing Society, p. 1, 2018.

[22] X. Ning, K. Gong, W. Li, L. Zhang, X. Bai, and S. Tian, "Feature refinement and filter network for person Re-identification," IEEE Transactions on Circuits and Systems for Video Technology, vol. 31, p. 1, 2021.

[23] J. Zhang, P. Zhang, and B. Xu, “Analysis of college students' public opinion based on machine learning and evolutionary algorithm," Complexity, vol. 2019, pp. 1-10, Article ID 1712569, 2019.

[24] X. Liu, Z. Liu, S. Yu, and T. Gong, “Adapted particle swarm optimization algorithm-based layout design optimization of passenger car cockpit for enhancing ergonomic reliability," Advances in Mechanical Engineering, vol. 11, no. 3, 2019.

[25] M. Mühlenthaler, A. Rab, M. Schmitt, and R. Wanka, "Exact Markov chain-based runtime analysis of a discrete particle swarm optimization algorithm on sorting and OneMax," Natural Computing, vol. 11, no. 5, pp. 1-27, 2021.

[26] H.-W. Kim, J. Kang, and Y.-S. Jeong, "Simulator considering modeling and performance evaluation for high-performance computing of collaborative-based mobile cloud infrastructure," The Journal of Supercomputing, vol. 75, no. 8, pp. 4459-4471, 2019.

[27] S. Deb, K. Tammi, X.-Z. Gao, K. Kalita, P. Mahanta, and S. Cross, "A robust two-stage planning model for the charging station placement problem considering road traffic uncertainty," IEEE Transactions on Intelligent Transportation Systems, vol. 17, no. 11, pp. 1-15, 2021.

[28] J. Huang, Y. Xing, H. You, and L. Qin, "Particle swarm optimization-based noise filtering algorithm for photon cloud data in forest area," Remote Sensing, vol. 11, no. 8, 2019.

[29] M. P. Hauer, X. C. R. Hofmann, T. D. Krafft, and K. A. Zweig, "Quantitative analysis of automatic performance evaluation systems based on the h-index," Scientometrics, vol. 123, 2020.

[30] Q. Gu, X. Li, L. Chen, and C. Lu, "Layout optimization of crushing station in open-pit mine based on two-stage fusion particle swarm algorithm," Engineering Optimization, vol. 53, no. 10, pp. 1-24, 2020. 
[31] M. Florez, E. Corral, M. Ochoa, and R. Fernandez, "Health care quality and medical competencies in the practice of emergency medicine: on-scene job performance evaluation," Emerge, vol. 24, no. 2, pp. 84-90, 2012.

[32] A. Farah, H. Hassan, A. M. Abdelshafy, and A. Mohamed, "Optimal scheduling of hybrid multi-carrier system feeding electrical/thermal load based on particle swarm algorithm," Sustainability, vol. 12, 2020.

[33] Z. Chen, "Consulting scheduling of vocational planning in colleges and universities based on improved genetic algorithms in journal of physics: conference series," IOP Publishing, vol. 1574, no. 1, pp. 1-6, Article ID 012168, 2020.

[34] M. Chatila, R. Sri Ratna, L. Svetla, and M. Michael, "The National Health Insurance System of Indonesia and primary care physicians' job satisfaction: a prospective qualitative study," Family Practice, vol. 39, no. 1, 2021.

[35] X. Tang, L. Jiao, W. J. Emery, F. Liu, and D. Zhang, "Two-stage reranking for remote sensing image retrieval," IEEE Transactions on Geoscience and Remote Sensing, vol. 55, no. 10, pp. 5798-5817, 2017. 